Article

\title{
Spationomy Simulation Game-Playful Learning in Spatial Economy Higher Education
}

\author{
Vít Pászto ${ }^{1,2, *(\mathbb{D}}$, Jiří Pánek ${ }^{3}{ }^{\mathbb{C}}$, René Glas ${ }^{4}$ and Jasper van Vught ${ }^{4}$ \\ 1 Department of Geoinformatics, Palacký University Olomouc, 17. listopadu 50, \\ 77146 Olomouc, Czech Republic \\ 2 Department of Informatics and Applied Mathematics, Moravian Business College Olomouc, \\ tř. Kosmonautů 1, 77900 Olomouc, Czech Republic \\ 3 Department of Development and Environmental Studies, Palacký University Olomouc, \\ 77146 Olomouc, Czech Republic; jiri.panek@upol.cz \\ 4 Department of Media and Culture Studies, Utrecht University, Muntstraat 2-2A, \\ 3512 EV Utrecht, The Netherlands; r.glas@uu.nl (R.G.); j.f.vanvught@uu.nl (J.v.V.) \\ * Correspondence: vit.paszto@upol.cz
}

Citation: Pászto, V.; Pánek, J.; Glas, R.; van Vught, J. Spationomy Simulation Game-Playful Learning in Spatial Economy Higher Education. ISPRS Int. J. Geo-Inf. 2021, 10, 74 https://doi.org/10.3390/ijgi10020074

Academic Editors: Wolfgang Kainz and Giuseppe Borruso

Received: 9 December 2020

Accepted: 8 February 2021

Published: 13 February 2021

Publisher's Note: MDPI stays neutral with regard to jurisdictional claims in published maps and institutional affiliations.

Copyright: (c) 2021 by the authors. Licensee MDPI, Basel, Switzerland. This article is an open access article distributed under the terms and conditions of the Creative Commons Attribution (CC BY) license (https:// creativecommons.org/licenses/by/ $4.0 /)$.

\begin{abstract}
Simulation games, as a method of playful learning, have been used for more than 70 years in various disciplines with the economy as a leading application field. Their development has been tied with advances in computer science, and nowadays, hundreds of simulation games exist. However, simulation games are not just useful for encouraging disciplinary knowledge production; they also promise to be effective tools for interdisciplinary collaboration. To further explore these promises, we report on the design and playing of a simulation game on the boundary of geoinformatics and business and economics; an interdisciplinary field we have termed Spationomy. Within this game, students from different disciplinary (and cultural) backgrounds applied their knowledge and skills to tackle interdisciplinary problems. In this paper, we also analyze students' feedback on the game to complement this aspect. The main goal is to discuss the design process that went into creating the game as well as experiences from play sessions in relation to this increase of interdisciplinary knowledge among students. In the end, we present a new gaming concept based on real-world data that can be played in other interdisciplinary situations. Here, students' feedback on individual features of the game helped to identify future directions in the development of our simulation game.
\end{abstract}

Keywords: interdisciplinary learning; tertiary education; playful learning; serious gaming; GIScience

\section{Introduction}

There are many benefits to making the educational process more playful. These include an increased motivation in students, a positive effect on high-level thinking skills, increased interest in subject matter, and a positive effect on general student achievement [1] The idea of playful or game-based learning is not new but stretches back centuries. In the 17th century, the Czech philosopher and educator Jan Ámos Komenský (John Amos Comenius, 1592-1670) already coined his well-known concept of "Schola Ludus" (School by Play; [2]) in which he promoted an entertaining way of learning. His main ideas focused on learning and teaching methods that build on authentic pedagogy, learning based on thinking, and cognitive constructivism [3]. This approach marked a departure from the memorization-based teaching of that time. Over the years, several authors from various fields worked with Comenius' approach also in connection to simulation games or serious learning (e.g., [4,5]). These days, serious gaming has become its own discipline [6], and game-based and playful learning techniques have become accepted by teachers worldwide, including in the fields of geography and economics (e.g., [7-11]).

So far, much of the research on game-based learning is focused on knowledge and skill acquisition within a specific discipline or a specific subject [12,13]. Despite that, games and 
simulations also hold promises to facilitate cross- or interdisciplinary collaboration and learning. Gee [14] argued that games have built-in learning principles that allow players to explore a learning situation from different perspectives (e.g., through role-play), thereby potentially encouraging interest in and empathy with different disciplinary perspectives as well as a reflection on the disciplinary "situatedness" of knowledge production. Furthermore, a game, as a rule-based framework, also restricts action opportunities and allows players to strive for a common goal, thereby facilitating collaboration and functioning as a kind of boundary object [15] and a cognitive frame [16] that provides a shared vocabulary to players with different backgrounds.

In this paper, we further explore the potential of games to facilitate interdisciplinary collaboration and learning by reporting on a game designed and played in the context of a three-year-long Erasmus+ project called "Spationomy-Spatial exploration of economic data: methods of interdisciplinary analytics" (for more information see $[17,18]$ ). Within this project, scholars and students from the fields of geographical informatics, economics, and related disciplines (e.g., geography, management, decision-making) were put together to explore spatial economic issues within a game context. This article can be read as a companion piece to another publication within the Special Issue Spationomy which focuses on the attitudes of students towards interdisciplinary knowledge. Using the technology acceptance model (TAM), and online questionnaires which were filled out before and after students' participation in the project, this research confirmed that "the Spationomy project has achieved its purpose, as both groups of students (economic and geography students) have acquired interdisciplinary knowledge and students intend to use it in the future" [19], p. 17. While we do offer insights from students gathered after the play sessions through evaluation forms, the main focus is on discussing the design process that went into creating the game as well as experiences from play sessions in relationship to this increase of interdisciplinary knowledge among students. It must be noted that interdisciplinary use and transferability of the presented game concept is suggested within fields that inherently, or even potentially, include geographical information and data. Thus, our game concept can be adopted to economic geography, economy itself, environmental sciences, local administration and regional spatial planning, and other socio-economic subjects exploiting real-world data.

Below we first offer an overview of research on simulation games and playful education after which we present a brief overview of the disciplines connected to the Spationomy project and present the key features of the project itself to provide the context in/from which the game evolved. There exists no complex game (to the authors' best knowledge) simulating real-world and data-driven scenarios in which direct collaboration of geoinformatics and economy students is needed. Therefore, we finally explain the game and analyze the results from the aforementioned evaluation of the game by students to explore how and to what extent the game facilitated interdisciplinary collaboration with regards to their fields of study. To that extent, the Spationomy simulation game approach presented in this paper introduces not only conceptual game design, but also students' experiences, which supplements the more quantitative results of the article on changing students' attitudes [19]. In the end, we believe that the main contribution of this paper lies in the game prototype that could be universally played, enhanced, modified, and adopted by any practitioner seeking to encourage interdisciplinary collaboration in related fields. In the Discussion section, we elaborate on the needed modifications for further interdisciplinary adaptations. We further discuss interdisciplinary aspects of the game concept and future directions in the article's conclusion.

\subsection{Related Work of Background Literature}

In general, there exist several works discussing how simulations are used or could be used in geographical education. The scope of this overview is to introduce readers to the world of games and its main keywords. Later, we focus on the games used in education, specifically in geography and economy educations. The goal of this section is to provide a 
general overview on related work in the domain of playful learning, rather than to list all of the possible games that could be facilitated in teaching and learning process.

\subsubsection{Simulations, Games, and Playful Learning-Education Perspectives}

As regards simulation definitions themselves, the comprehensive work of McCormick [8] provides several ways the simulations can be defined and, furthermore, he explains steps in creating and applying the simulations in education. For instance, one of the definitions in [8], formed earlier by Twelker [20] states that "a simulation is a means for letting learners experience things that otherwise might remain beyond their imagination, a means to practice skills safely and without embarrassment, and perhaps even discover insights into actual problems". The key element of this definition is the point that the simulation is a method by which the learner or participant can be involved at the center of the problem under investigation [8]. Moreover, participating students are way more "mentally" towed towards the simulation process (ignoring or mishear orders from a teacher), which forms a creative and engaging atmosphere in terms of learning-by-doing. Moreover, according to Csikszentmihalyi [21], there is a phenomenon called a "flow" in experiential activities of humans (to which playful learning and gaming as such belongs), which is explained in [21] as "joy, creativity, and the process of total involvement with life". Later, Krek [22] mentioned a "flow" in connection with urban spatial planning.

The first wider understanding of games and simulations as teaching techniques appeared in the late 1960s (e.g., the pioneering work by [23]) and 1970s. In these days, the games were considered an innovative approach in the learning process (e.g., [8]). Geography scholars followed the trend and further development of the theories on using games and simulations in geography in higher education. The work of such scholars includes the research of Conolly [24] who described how various four games could be modified and incorporated into geography classes. Furthermore, Walford [7] referred to how geographic games and simulations replaced traditional educational methods, which happened to be dissatisfactory. Walford [7] further advocates that the simulations combined with experiential learning (see [25]) are valuable new aspects in the learning process. He summarizes the research by listing four important aspects:

- games and simulations improve student motivation,

- games and simulations create a better teaching atmosphere,

- games and simulations help to fulfil more rigorous and ambitious educational goals,

- games and simulations encourage the more effective learning of subject-matter.

Interdisciplinary collaboration, which is a base concept for our simulation game, is omitted in his summary. On the other hand, he critically elaborates on the disadvantages of games and simulations in teaching, especially the preparatory phase, debriefing, and the overall fit into a study program [7]. In the same year as Conolly and Walford published their research (i.e., [7,24]), King [9] discussed the usage of games and experiential learning in geography education. Nowadays, it can be observed that digital technologies play a vital role in gamification and edutainment. Google Earth can serve as an illustrative example of a relatively recent groundbreaking product, that is neither a game nor a simulation, but still "gamifies" the education process despite being "just" a popular online service. Other efforts of "making geography human" can be seen in popular digital (map)storytelling (e.g., [26-28]). SimCity series, an open-ended city-building simulation video game, became one of the most known examples of simulation games used for geography teaching (e.g., [29]). Furthermore, business simulation games such as Transport Tycoon (e.g., [30], or [31]), or historical strategy games Civilization (e.g., [32]) or Age of Empires [33] used the asymmetrical structure where the players start with unequal assets, which enhances the potential variations in the emergent narrative [34]. All of these games had the map component incorporated in the game mechanics and allowed the players to use their geo-skills in order to succeed in the game.

The business simulation games, like various Tycoons (Transport Tycoon, Railroad Tycoon, Theme Park or Capitalism), connects a simplified geographical environment, for 
example for transportation, with the business/economy and local geopolitics. In 2009 the 3D block generated world of Minecraft was introduced, and it was used in various teaching (e.g., [35-37]) as well as research [38-40] projects. Minecraft can serve as a learning tool, and after being bought by Microsoft in 2014, the educational version was released in 2016. A detailed study on how Minecraft is used in education and research is provided by [36]. However, all of the games mentioned above do not explicitly address spatial economic topics, let alone topics based on real-world or data-driven scenarios.

\subsubsection{Simulations, Games, and Playful Learning in Geoinformatics and Economy}

In GIScience (geoinformatics), one of the significant exploration of playful learning (or games in general) in the field was assessed by Poplin (at the time named Krek) in the late 2000s in [22]. Generally, she sets gaming in public participation processes. Also, she mentions spatial planning games (e.g., PlastiCity: A Multiplayer Urban Planning Game, Urban Plans, or City Creator) that might complement applications/games above. A serious game for educational purposes implementing GIS was emphasized by $[41,42]$. Urban spatial planning is a perfect domain, where simulation games are applied (e.g., [28,43-46]) as it encompasses various aspects of urban life including its economies. In other words, the domain of spatial planning is an ideal spatial-economic laboratory for playful learning. Some of its real-world topics were adopted in a Spationomy simulation game too, such as it motivated us to play the game in (digital) build environment settings-i.e., using urban spatial data. It is also worth mentioning at least two recent online games that include spatial and economic aspects (together with disaster management), namely FloodSim (https:/ / playgen.com/play/floodsim, accessed on 8 February 2021), and Stop Disasters! created under the United Nations Office for Disaster Risk Reduction (https://www.stopdisastersgame.org/, accessed on 8 February 2021). In the past halfdecade, the noteworthy spread of augmented (AR) and virtual reality (VR) applications into geography education has taken place across the globe (e.g., [47-50]); and it seems that such tools and applications will be a flagship in modern digital and playful educational methodologies. A recent special issue of ISPRS International Journal of Geoinformation (IJGI) on gaming and geospatial information brings collections of nine papers dealing with gameplay aspects in connection to GIScience. From those containing an educational domain, it is worth mentioning a paper by [51], in which authors explore serious geographical games to support spatial thinking in connection with disaster resilience. More specifically, their paper introduces Project Lily Pad as a game in a 3D environment to support spatial thinking. However, as the authors of the article [51] admit themselves, the game lacks more realistic scenarios. Hence, the game does not contain analytical tools and aims at map-reading and navigation skills. In another paper [52] in the special issue, Robert Olszewski and his colleagues are developing a game prototype that will enable online sharing of spatial information, analysis of environmental data, and even modelling changes in the environment. They use an engine from Cities: Skylines with extensions enabling to import topographic and thematic data. The use of Minecraft for educational purposes of young children is described in [53] of the IJGI special issue. The paper illustrates the inter-connection between Minecraft, already mentioned above, and urban planning (as a "playground" ideal for gaming and education).

When we move from geographically oriented games to the economy/business domain, Faria et al. provide [54] a comprehensive overview of (pure) business simulation games. The authors explored papers published in the Simulation $\mathcal{E}$ Gaming journal, where crucial advancements in business gaming in the history of the last 40 years before 2008 were mentioned. Authors also discussed the topics covering technologies in business games, how business games are administered, and about current (in 2008) nature of business simulation games. Furthermore, the authors provide evidence of how other researches traced a history of business games nearly 5000 years in the past when the first board and war games were developed. A Russian social scientist Mary Mironovna Birshtein developed the first modern business simulation game in 1932 by adapting existing wargames. Her 
"game" simulated the assembly process at a typewriter factory in order to train future managers on how to solve production problems [55]. Twenty years later, the first American business simulation game was launched in 1955. The RAND Corporation (prestigious American research institution) came with simulation application focusing on U.S. Air Force logistics systems with the goal to train inventory managers in a simulation of the Air Force supply system (today, it is a typical example of the role of business managers). From that time, a variety of business simulation games were introduced and, for example, famous Mary Birshtein's game was modified into a new 40 versions. Over 100 different business games existed just in the U.S. by 1961, and this number more than doubled to 230 business simulation games to be used in the United States by 1980 [54]. Reports from Faria et al. [54] notes that more than 30 different business simulations were available in Eastern Europe in 1980, and around 200 business games were used in German-speaking countries by 1985.

\subsubsection{Spationomy Simulation Game in the Context of Playful Learning}

As the simulation game represents the Spationomy main playful activity, it is worth mentioning the main difference between "simulation" and "game" (differences summary is based on [8,56-58]). In games, opposite to play, there are usually rules based on which a winner is determined. The key agents are competitors (individuals, teams, environments, computers), who attempt to reach an objective (e.g., complete a game round task) with actions within the pre-set rules. Furthermore, a game is often complemented by a feature(s) to make it fun for a player(s), while still serious enough to keep attention and focus. Different games can embody different types of competitors, such as individuals or teams, as well as artificial intelligence. Players can also play against the game itself. At the same time, the simulations do not necessarily need to produce a winner(s); in some cases, the simulation can be about the investigation of possible ways to solve a real-world problem. One example of this is the variety of the Tragedy of Commons simulations that includes Fish Banks from Denis Meadows, the author of Limits to Growth [59]. Games, as well as simulations, usually include the key element of decision-making, which allows a learner to make decisions - the most valuable attribute of playful teaching. Such a need stimulates learners' cognitive abilities (thinking) and forces him/her to act upon his/her conclusions in order to successfully finish the game [8]. Playful methods, whether or not they are games or simulations, can be framed in a concept of "learning-by-doing", from which a learner can carry off more into his/her real-life.

The Spationomy simulation game, as presented in this paper, represents a methodological approach aligned with "learning-by-doing" with an extension to interdisciplinary collaboration and mutual learning. The game was conceived and designed from a constructivist pedagogy perspective, in which successful learning is linked to active participation in the learning process by students, and elements like using authentic problems, engaging in communities of practice, and approaching problems from multiple perspectives, is key [60]. Following Gee [14], such a constructivist approach has the potential to trigger not only active and critical learning but also master, at some level, "semiotic domains [i.e., an academic discipline with its own practices and situated meanings], (... ) and critically think ( . . ) about the relationships of the semiotic domain being learned to other semiotic domains." [14], p. 49-50. This approach plays to the strengths of what games can offer and is fitted best with a strong interdisciplinary aim of the project.

Additionally, the Spationomy simulation game contains all four features of "games" as identified by Crawford [61]: Representation, Interaction, Conflict, and Safety. We further explain these four features in [62]. In Ref. [16], the authors suggest that a game is a system in which players engage in an artificial conflict, defined by rules, that results in a quantifiable outcome, while [63] defines a game as a rule-based formal system with a variable and quantifiable outcome. By looking at the Spationomy simulation game from a perspective of game design, we can claim that our game meets elemental features to be treated as an environment for playful, interdisciplinary, and collaborative learning. 


\section{Spationomy Project and the Simulation Game Conceptual Framework}

As mentioned earlier, the concept of the simulation game has been developed within the three year Erasmus+ project called "Spationomy" within the program of the Strategic Partnership in the field of education, granted by the European Union. Economic data analysis is a vital part of the decision-making process. The importance of the geospatial component inherent with the most economic data is increasing, and the literature also reflects the fusion of economy and geography (geoinformatics) (e.g., [64-66]), which proves the importance of spatial aspects of economic analyses. Even in the modern gaming industry, the spatial component and game spaces play a crucial role since they can evoke narratives that the player engages with [67]. In the project, we intended to go further in the sense of incorporating spatial thinking and skills directly into playful learning. The project's main goal was to establish a platform for knowledge exchange between teachers and students (undergraduates and graduates) in the fields of geoinformatics, geography, economy, and business informatics. The project aimed to share best practice across disciplinary and national boundaries and to develop deep interdisciplinary cooperation and research sharing among the involved institutions in the field mentioned above. The major teaching/learning part of the project was blended mobility composed of two physical and three virtual meetings (see Figure 1).

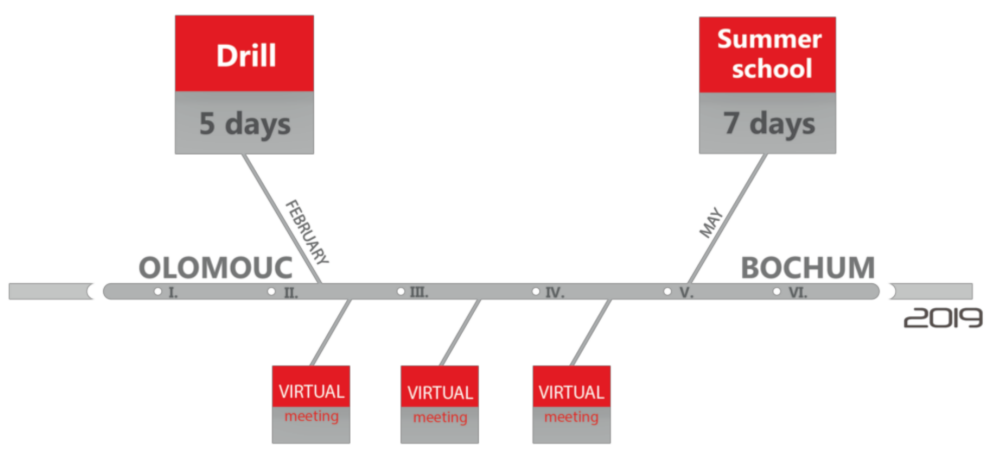

Figure 1. A timeline of the last year's blended mobility of the Spationomy project in 2019. Source: authors.

Every Spationomy cycle took about four months, and we structured it into two physical meetings and several virtual meetings. The first physical meeting (labelled as "a drill part") was organized at the beginning of Spationomy cycle as an intensive course, where all the participants even their knowledge about the disciplines they are not familiar with. The main goal of the drill part was to find a common scientific language between all participants. After the drill, students worked in international teams on their thematic projects that were assigned at the end of the drill. The thematic project represented a blended mobility activity during which students cooperated on a common topic covering geoinformatics and economy. For this purpose, students used various collaborative tools, such as online (virtual) meetings using VoIP (Voice over Internet Protocol) telephony, Facebook groups, direct messaging, or shared documents. The second physical meeting-a summer school-represented the last part of the cycle where all participants deepened their interdisciplinary skills and knowledge via a series of workshops, practices, lectures, and field trips. Specific geospatial knowledge and skills trained during the project included working with data sources, advanced data management (geospatial databases), static modelling using GIS overlay operations, network analysis, gravity modelling, interactive online geovisualisation (QGIS2Web plugin, ArcGIS Online and StoryMaps), to name a few; all delivered with outreach and application to economic topics. At the end of the summer school, students served as actors in "economic/business analytics game" (later rebranded to "Spationomy simulation game"). A thorough description of the game is provided in the next section. Project participants were from Moravian Business College Olomouc and Palacký University Olomouc (both Olomouc, Czech Republic), University 
of Maribor (Slovenia), and Ruhr-Universitaet Bochum (Germany). The group comprised of 28 students per year from (under)graduate-level covering geoinformatics, geography, economy, and business informatics equally.

\subsection{Spationomy Simulation Game General Set-Up}

Within the Spationomy project, the pedagogical goal was to evaluate the prospect of playful and experiential learning in combination with simulation game(s). This was positioned into the context of an interdisciplinary and international learning environment. In order to reach the goal, the simulation game scenarios were modelled onto the real-world problems and their solutions. The simulation game was designed as a group-based and student-led investigation of advanced economic and spatial data. The main goal of the game was to encourage students to apply the knowledge and skills they gained during the project activities through a competitive and interactive environment. The gaming settings were designed to entail relevant methods from geoinformatics and economy in a way that students had to think about and use properly. Instead of mechanical repetition of GIS analyses, often used in "normal" teaching as practices, students were encouraged to accomplish given tasks with a certain degree of creativity. Playful environment and real-world settings of the game helped them reinforce the knowledge and their skills acquired during preceding project activities. Students were active agents in stimulating issues from the real world via a series of game rounds and worked in international groups (four students, one from each participating university). In order not to limit the students' gaming comfort in any way, they could use their own computers. However, computers with necessary software (e.g., MS Office, ArcGIS, QGIS, R-project, etc.) were available for them in the university computer lab. Regarding the specific GIS software and tools, the most used were QGIS (newest versions at the time), and two Esri products-ArcGIS Pro and ArcMap with necessary extensions and plugins (e.g., Network Analyst, Spatial Analyst, Market Analysis Toolbox, etc.). It has to be noted that available GIS tools also depended on the host institution. However, from the three iterations of the simulation game, QGIS was once the only option. As regards the input data, students were always provided with real (or near-real) geospatial layers. It forced students to practice their data management skills (attributes exploration, metadata search etc.), unlike using static thematic maps. Students could also use all the materials available from the Spationomy e-learning system, and if viable, they were not restricted to cooperate with other teams; nevertheless, this option was selected only by a few teams each year. As regards the simulation game timing, every round lasted $90 \mathrm{~min}$ in which students had to deliver the required output. The only exception was the initial round that lasted a half-day lecture time (180 $\mathrm{min})$ where students had to solve more tasks (see description below).

After every round, students had to report their progress by sharing the required output with the "game-masters". Depending on the type of the round, students provided a map project, pictures, presentations, results of the deal with another team, or calculations for a given round. The game-masters double-checked all the outputs, and after each round, students were ranked based on various criteria. The winning team was ensured by defining objective measures (scores) which served as a proxy for overall rankings. However, sometimes we were not able to evaluate students on the basis of numeric scores for specific game rounds (e.g., in case students had to provide marketing materials). Therefore, game masters (staff members) collectively and expertly rank the teams in terms of overall performance during the round. Game masters evaluated the quality of created materials (logotypes, branding, overall carefulness of formal documents), and their teamwork flow, to name a couple.

The thematic content of the simulation game rounds was designed in such a way that it kept a balance between geoinformatic and economic focus. That was ensured by sharing responsibilities within the game-masters team during the game preparation, so every project partner designed an independent and versatile simulation game round. All simulation game rounds (except the initial setting-up round) were created in a way that 
allows them to be played at any stage of the game- the rounds are not dependent on the previous (or next) round, which gave them desired versatility (Figure 2).

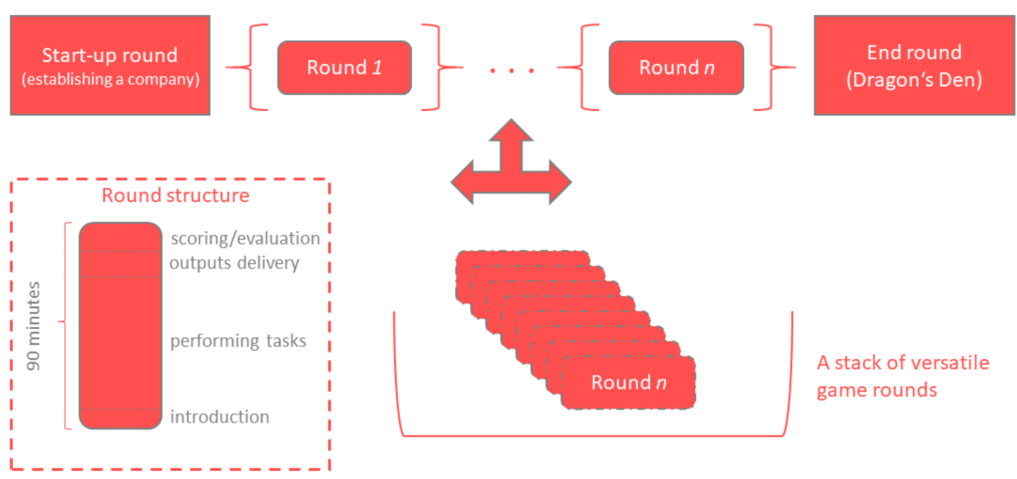

Figure 2. Spationomy simulation game conceptual framework illustrating universal and versatile usage of gaming rounds. Source: authors.

\subsection{Game Rounds}

As the main idea of the game was to combine geographical and economic topics and students, we had to come up with the scenario that would allow us to do so in a smooth way. At the beginning of the whole simulation game, students virtually inherited three million Euros from their grandmother, who was a successful bicycle racer. In her last will, she expected them to continue the family tradition in the bicycle-making business. Hence, the start-up round was set to find an optimal location for building a new bicycle-making factory, create the name and logo of the company and think about the marketing strategy. There were several rules regarding where the factory can be built, and students had to calculate and analyze an optimal location accordingly (based on geospatial data they were provided with):

- To build one square meter of the factory, it costs an amount according to the real zones of a price map of Olomouc (Figure 3), so students had to calculate the prices of the plot for the factory using the zones of price map.

- Students were not allowed to build the factory on the roads/railways/rivers/lakes/ and other places generally not suitable/accepted for factory buildings. If they planned to make the enterprise in an "open space" area (field, non-urbanized area etc.), they need to pay the price for a square meter according to the price map. If the factory was planned in a place where other building(s) already exist(s) (according to the aerial image), they had to purchase the property first (according to the price map). They then paid the price for a square meter according to the price map. In other words-the factory costs double.

- Only one-story factories were allowed and should be a rectangular shape, while every 10 square meters need at least one employee, but a maximum of three employees per 10 square meters are allowed (three-shift work). Employees had to be paid an average monthly wage in the Olomouc region, which is 933 EUR (based on the average wage in 2017). One employee can produce one bicycle per month.

- The companies were categorized into three classes based on the number of employees (micro, small, and medium-sized). This classification also reflected the selling price of the bicycles, where micro-sized companies sold fewer bicycles for higher prices (2300 EUR), while medium-sized companies sold more bicycles for a lower price (2100 EUR).

- Operational expenditures (other than salaries) were $85 \%$ of wages per year. Factories were also producing some pollution. The total amount of pollution was calculated based on their bicycle production as the number of bicycles made per year multiplied by one ton. 


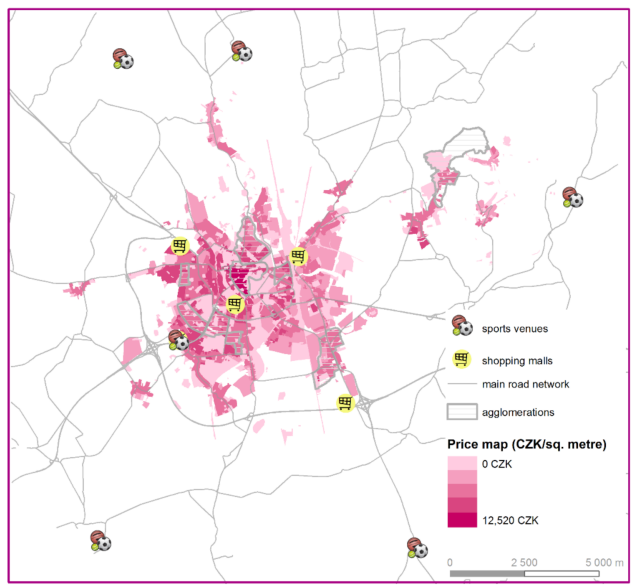

Figure 3. A gaming location with price map and bonus site allocations used for the start-up round. Source: authors.

For all the regulations mentioned above, we have used real data layers from the Olomouc region, Czechia (Figure 3). There were also two types of bonuses students could get when locating their factory - the first bonus was linked to the proximity to the main road network, due to the better logistics. The second bonus was awarded if the factory was located close to the main shopping malls or sports venues, as it allows easier access to main markets. The outcome of the set-up round was the factory location together with the name/logo of the company and marketing strategy. The location of the factory was permanent for the rest of the simulation game, so it was crucial students place their factory in an optimal site. At the end of the initial round, the students delivered a shapefile (.shp) with factory boundaries and calculated price of the plot. Their calculations were cross-checked by the game masters and filled into the game scoring system.

The start-up round was followed by five to six specific rounds (varied each cycle of Spationomy project), in which students' team compete with each other (see teams in action in Figure 4). Complete list of versatile game rounds with description is given here:

- Floods-Several severe floods hit Olomouc in the past 30 years. Since floods are one of the most frequent natural threads, this round simulated a natural disaster of this kind. We provided students with the flood zones layer from 1997 (the most severe floods in the modern history of the city, when one-third of the city was flooded). We slightly expanded the flood zones manually in order to involve more students' teams. In total, four flood zones were defined ( 1 to 4 ; 1 -severe damage, 4 -no damage). This round combined the economic as well as the geographical background of our students, as they needed to calculate how much the floods affected their factory. Moreover, if the factory was flooded, they had to evacuate the employees to the evacuation center with minimal costs (performing a network analysis in GIS). From a geospatial perspective, teams had to follow limitations and impedance factors, such as distance costs (0.5 EUR per kilometer), time costs (four Eurocents per second), maximum speed reduction based on the location of roads in a flood zone. To solve the optimal routing problem, students had to select roads by location first, and then calculate impedance values for each road segment in the attribute table.

- Find a Supplier-Competing teams had to apply their skills in MS Excel table data management. Students were asked to filter the data with several thousands of records for a specific company that will become their supplier. They had to focus on particular economic measures, e.g., return on equity, equity, assets turnover, financial leverage, and geographical distance from their bicycle factory location. Moreover, they were provided with different weights of these measures in order to make the decision process more complicated. This game round was designed for (and oriented to) team members with economic studies background. No geospatial layers were provided 
as students used their preferred tools to geocode suppliers' locations and measure geographical distances.

- Municipality Public Call on Bike Sharing Project-During this round, students had to prepare a proposal for a new bike-sharing service. The Olomouc City Council has decided to support environmental-friendly transportation in the city. Therefore, the Council would buy new bicycles as the introduction of a new system of bikesharing. Students should follow obligatory requirements such as lowest price offer (in "blind" bidding system), the municipal budget could afford only 1200 bicycles with a maximum price of 3000 EUR per item, and students' companies can allocate up to $20 \%$ of their overall bicycle production capacity. From a geospatial perspective, the bicycle-sharing project must contain ten docking stations located under some spatial constraints. These included conditions such as stations must be at least $400 \mathrm{~m}$ from each other but maximum of one kilometer, and stations must be placed in the most frequent cycling routes (based on Strava data provided by game masters), and in the densest employer zones (based on employer density layer). Students also had to complement their proposal with a graphical dashboard and map visualization of docking stations. The geospatial skills practiced in this round contained different data sources combination, proximity measurements, and overlay operations.

- Pollution Allowances-This round was designed to engage students in negotiation practice. Students would experience live interaction and bargaining about the pollution allowances. The emission limit for the game world (Olomouc region) was set to $70 \%$, and students could not invest in reducing emissions (e.g., ecological improvements). Students had to purchase emission allowances in auctions from the state (environmental exchange) to cover all of their emissions by allowances; otherwise, they were penalized. Some teams decided to gamble and buy more allowances than needed and then sell them with profit to other teams. Nevertheless, the allowances were sold to the highest bidder, so students had to gamble first and bargain afterwards. This round contained no additional spatial (geographical) features or data layers; the number of produced bicycles drove pollution produced by the company.

- Market Share-This topic focused on the application of gravity modelling, namely the Huff gravity model within a GIS environment (e.g., [68,69]). The tool enables to calculate "service" areas of given event points (bicycle factory locations in this case) and to include potential new location of another company branch to recalculate the new services areas (market share). The idea of this round was that every team could extend its market share (service area) by moving or splitting their current factory location. At the same time, students should also presuppose other teams' intentions. The emphasis was placed on the strategic decision-making and anticipation of other's behavior. From a geospatial point of view, this round practically introduced students to the topic of spatial interaction modelling used frequently in economic geography. More specifically, students learnt to work with Market Analysis Toolbox for ArcGIS. In this round, students used data from the start-up round and point data locating other teams' factories.

- Market Share Analysis-This round differs from the previous one (Market share) in several aspects with one key feature-the teams could cooperate with another team to share expenses for building up a new joint company branch while doubling their service area. Spatial constraints included a maximum distance of $400 \mathrm{~m}$ for a new branch (or $800 \mathrm{~m}$ if teams cooperate). Moreover, the service area was calculated using "normal" network analysis in GIS, instead of a gravity model. For this purpose, students were given a road network layer of the study area. Their revenues were derived from the number of inhabitants (based on address points layer available from game masters) that live in the newly created service area. This round should have encouraged cooperation among teams, rather than competition, since a widening of the market share area might bring more revenues. The main geospatial learning goal 
in this game round was to practice network analysis by the creation of service areas based on distance.

- Location for Reseller Shop-This round was designed for practicing geospatial tasks covering analytical search of an optimal location for placement of a new bicycle shop. Students had to apply geospatial tools following given restrictions and limits (e.g., a new shop must be placed only in a district with certain population density). This round was mainly geographically focused, thus most of the workload was given to "geo" team members of the student teams. In this round, from the point of GIS analysis, students used basic overlay operations and proximity tools (such as buffering), selection in attributes, and Thiessen polygons. Since these analytical tools are simple to use, students were forced to act under time pressure. There was only a limited number of available sites they could select.

- Investment into Renewable Energy Sources-This round focused on the teams' decision-making process, based on net present value calculation usually deployed in investments and revenues optimization. As this round was focused mostly on economic issues, the "economic" members of the team carried most of the responsibility for a final decision. The only geographic task for teams lied in the identification of the renewable energy zone (geospatial layer prepared and provided by game masters) to which their company belongs.

- Spationomy Dragons' Den-The final round was focused on the overall presentation of the students' projects (business). This round was inspired by successful TV series, broadcasted in the United Kingdom under the name "Dragons' Den", in the USA as "Shark Tank", and in more than 30 countries worldwide. Students could "sell" exciting ideas and business plans presenting their products to wealthy investors ("game-master") to get investment for their entrepreneurship. No spatial task was set for this round.

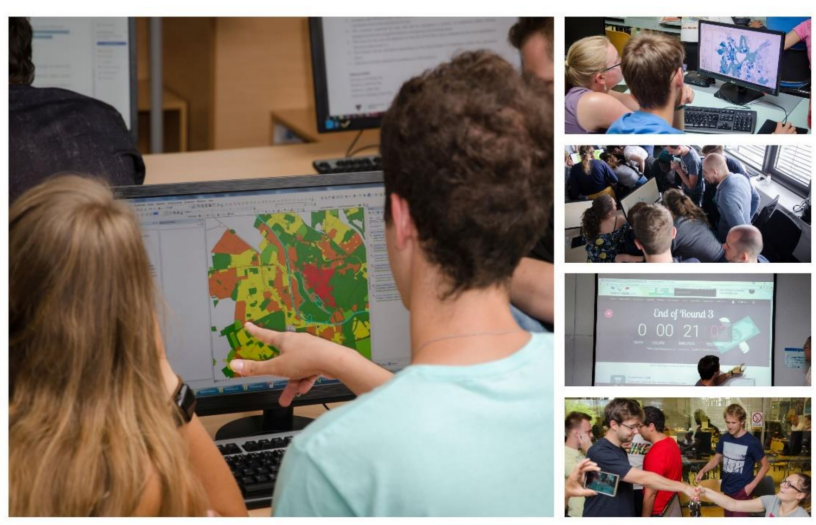

Figure 4. Illustration of the simulation game working environment (performing analysis, discussions, deals). Source: authors.

Complete description and game-rules of the simulation game and its rounds, as well as datasets, are freely available in the Downloads section of the Spationomy project website -https:/ / spationomy.mvso.cz/, accessed on 8 February 2021—and partly in [62].

\section{Evaluation of the Spationomy Simulation Game}

The evaluation of the game was done at two levels-one was the authors' evaluation of the game mechanics and process within the game, the second was the evaluation done by students regarding their involvement in the game. In this chapter, we will focus on the students' evaluation of the game, specific rounds and the teaching/learning elements of the game. Our simulation game evaluation qualitatively complements a statistical evaluation using TAM (e.g., [70,71])—whose results have already been described in [19,72]. Our approach to student feedback confirms the game debriefing as a necessary step in 
game design [73]. Students' remarks represent additional and authentic insights into the game structure description. In this sense, we constructed some finding of students' performance in the simulation game, based on the exploration of their responses/data. According to [74], exploratory research uses "exploration" as a keyword. Exploration emphasizes the development of the theory (in our case, we rather refer to findings) from data; unlike qualitative research as such, which emphasizes methodology and data by which this development is achieved [74], p. 4. Thus, the evaluation of students' feedback should be approached in this manner.

In total, during the project lifespan, we played three simulation games; each year updated and modified in terms of new rounds and their order. After that, students evaluated the simulation game through a simple questionnaire. Students were asked to evaluate their decision-making process within the team, simulation game design, and technical aspects of the game. Moreover, we recorded their gender composition, level of study, and home university as auxiliary data. In total, 60 students took part and replied in the survey, 20 students in the first year and 13 in the second year of the project and 27 in the last, third year of the project. When having a deeper look at the background of the students, almost two-thirds (61\%) were bachelor students, while only $39 \%$ were master students. The gender rate of respondents was quite balanced, with $53 \%$ males and $47 \%$ of females responding to the questionnaire. What is interesting is their lack of experience with simulation games in the educational context, when $87 \%$ of them replied they have no experience with such simulations; $6.5 \%$ replied Yes, and what may be confusing, $6.5 \%$ replied Maybe - does that mean, students are not able to identify what a simulation game is? Although we aimed to have a balanced group regarding their background, we had slightly more students (54\%) with geographical background, than students with economic background (46\%).

\subsection{Decision Making}

As regards the decision making in a team, which was dependent on a gaming nature and tasks in individual rounds, the answers varied from $37 \%$ to $85.2 \%$, and the students mostly agreed that "Decision making was done collectively (based on majority agreement)". This is pinpointed by one of the comments from a student: " ... an interesting feature in the game was a need of teamwork ... " (female, Ruhr-Universitaet Bochum).

Students could also choose from other two options-"The team was indecisive, and we used "trial-and-error" method" and "There was one leader, and we followed his/her instructions (decision made by the leader)". The percentage of the answers to the two latter questions changed with respect to the structure and complexity of the task in a given round. Regardless of the decision-making process itself, the majority of the students indicated that they were satisfied with the final decision of their team. We used a 5-point Likert scale, and $70 \%$ of students marked 4 or 5 in terms of their satisfaction, where one stands for the lowest, and five for the highest.

\subsection{Knowledge Gain and Interdisciplinarity}

A next step is if and how the game would translate into the perceived knowledge gain. Generally, from the thorough quantitative evaluation of the project, it was statistically proven in [19] that perceived usefulness and ease of use of new technologies (GIScience in our case) influence behavior intentions of the user, which was to gain interdisciplinary knowledge of geoinformatics and economy. As a result, the interdisciplinarity stimulates cooperation on cross-disciplinary topics [19], which consequently implies new knowledge gain. As regards the simulation game evaluation itself, two questions were aimed at this topic. The first question "Did you use knowledge and skills acquired within the previous Spationomy activities for the simulation game?", which related to the connection between the learning activities preceding the actual simulation game during the summer school, and the actual engagement with the game itself during the summer school. The question was answered very positively with $48 \%$ answering "Yes" and $48 \%$ answering "Some of it", 
leaving only $4 \%$ answering "No". The second question focused on their perceived future use of the knowledge they acquired in the project activities preceding the simulation game. The question was formulated as: "Did you find the knowledge, skills, and experiences acquired during simulation game useful for your future studies/profession?", 53\% of students answered "Yes", 40\% answered "Some of it" and 2\% answered "Hope so", leaving $5 \%$ with the answer "No". In general, students were positive about the usability of new skills and knowledge they learnt via project activities. For instance, one of the students noted that: "Mixing knowledge was the most interesting aspect of the game" (male, University of Maribor). Such a positive evaluation motivated and ensured organizers in the concept of the simulation game as interdisciplinary and collaborative proxy for learning. Students generally appreciated the interdisciplinary nature of the game, mentioning that: "The cooperation with not just foreign students but also with students of other fields of study" (female, Moravian Business College Olomouc). Other student added: "One of the most exciting aspects of the simulation game was links between different nationalities and disciplines" (male, Palacký University Olomouc). However, the interdisciplinary approach must be further developed as some students indicated they would also like to have even more links between economic and GIScience activities. This was described by one of the students: "Maybe more focus on the interconnection between "geo" and "eco" activities." (male, Moravian Business College Olomouc). This answer signaled that we need to better communicate knowledge gain as fundamentally interdisciplinary, as an answer to a question about the inherent interdisciplinary core of the whole project-how to connect geographical tasks with economic tasks-indicated that this was experienced throughout. To provide context- the interdisciplinary aim of the project was to present each game round as a fundamentally interdisciplinary endeavor, with all students required to provide input and as a result share knowledge and skills. While the game design team did make an effort to create this as a basic starting point for each round, in the end not every round could be fully designed to involve students equally from each study field. An underlying challenge was also the often-disciplinary teams of teachers supervising groups (an issue discussed below). Therefore we asked student, "How did cooperation between "geo" and "economic" team-members go (for all rounds)?". The answers surprised us in a positive sense, $64 \%$ of students stated that "Cooperation and decision making was well-balanced". This shows that even in rounds that did not offer cooperation, all students had an equal disciplinary input. Nevertheless, as a whole, the Spationomy game was experienced as an interdisciplinary exercise, with only small percentages of students indicating that some perspectives were dominant over others during cooperation and decision-making.

\subsection{The Playfulness of the Simulation Game Rounds}

An important aspect of every game lies in its playfulness-either the playfulness inherent in the tasks themselves, or the whole process of the game (including soft skills). We have asked students "How playful was each round?" in the evaluation form, and the students had the opportunity to answer again via five-point Likert scale ( 1 lowest -5 highest). The average value in the first year was 4.0, in the second year 3.9, and 3.5 in the third year. We identified a cause of this slight decrease of playfulness to be the addition of new rounds in consequent years. This made the simulation game more complex and demanding, which affected the overall perception of the game playfulness. Nevertheless, there were differences among rounds. For example, the least playful round (Renewable energy investment) had an average value of 2.6 and the most playful round (the Dragon's Den) had an average value of 4.5. Students tended to assign more positive values to the tasks, where the degree of interactivity with others is high, or where there is an element of surprise as a game-changer. One of the students reflected on this in the evaluation stating that we can "add an unexpected situation (for example Economic Crisis)" (male, Palacký University Olomouc). When asked which features students found the most exciting, in each year most answered: "decision making - tactics and strategy". We were also interested to know how much the students risked in each round, and therefore the question "In which 
round(s) did you risk the most?" was part of the evaluation process. The most answers $(43 \%)$ were gained in the Pollution allowances round, which is the round where students had to gamble first and bargain afterwards.

Students furthermore appreciated the variability of the tasks and interaction within the game. When asked "what was the most playful/interesting/exciting aspect of the simulation game?", the replies included "The variability of tasks and changing conditions from round to round, that we always got a new chance to win the round and never have tempting to give up based on the previous results" (female, Palacký University Olomouc), "the interaction with other groups and planning together" (male, Palacký University Olomouc), and "dynamics of all participants within and outside the teams. I enjoyed it!" (female, Ruhr-Universitaet Bochum).

The survey results indicate that games like the Spationomy game have the potential to facilitate effective collaboration by (a) providing a common framework and vocabulary, (b) encouraging empathy with or curiosity towards the other disciplinary perspective, and (c) encouraging reflection on the (assumptions in the) respective disciplinary backgrounds by more playfully engaging with the topic at hand.

\section{Discussion}

Building any simulation game is a complex endeavor, where proof-of-concept, beta testing, simulation rounds and evaluations are crucial parts of the long process of game development. As identified earlier by [75], there are also the more generic challenges of incorporating features of games and gamification in (higher) education. These include fitting in such playful activities in existing, more traditional lectures; the amount of time such activities subsequently take; having enough classroom space actually to play in and dealing with behavior management of learners (including cheating and other play-related loopholes). While we recognized all of the above in our project, in this section, we plan to discuss project-specific findings more based on insights coming from students' evaluation with our observations acting as "game-masters".

Firstly, from a game design perspective, we faced a lack of time (especially in the first year of the project) in the preparatory phase of the simulation game since we had no formal education in game design. This resulted in fewer (but well-prepared) rounds in the first year as it comes to bug-free game rounds. On the other hand, this experience helped us to plan the next years of the game well in advance. When playing individual game rounds, we encountered small issues raised by the students-for instance, in the start-up round students asked if they can build their bicycle factory in an area with already existing buildings. This was not thought about in the round design; therefore, we managed to improve the rules for the next years by adding extra costs for existing buildings demolition.

Similarly, issues with price setting and its related gameplay bonuses, or balancing gameplay with real spatial data sets in order to create a fair distribution of difficulty between players groups, turned out to be challenging. While working on the floods round, we were not able to provide students with a real digital elevation model (DEM) of the study area and some students, especially those with local spatial knowledge, questioned the flood zones we provided. The zones were thus manually expanded in order to ensure that most of the team would face a roughly equal challenge with flooding-related issues around their factory. This highlights not just the benefits of - or basic need for-a more iterative approach to designing educational game content over time-it also highlights the necessity to take local situations as well as the situated, cultural knowledge of participants into account. From a game design perspective, this means a one-size-fits-all approach to creating games like these seems inadvisable.

Additionally, it was decided early on that the process of the creation of individual rounds had to be self-independent. This allowed learners as well as round creators to focus on specific issues at hand rather than constantly seeing these issues concerning previous or upcoming game challenges. Since all of the Spationomy team members (game master and game rounds designers) professionally come from different institutional/departmental 
fields of study and were often also grouped accordingly (i.e., geography, geoinformatics, economy, business informatics), it became a very complex task to coordinate and to develop a flawless "chain" of follow-up rounds. While this worked well on the level of the rounds themselves, the game experience as a whole could feel incoherent.

However, in the end, the game concept was finalized as an open and flexible framework allowing future adaptations for interested academics. We believe the transferability of the game in terms of employing real-world data allows other disciplines to adopt the concept. Subjects like economic geography, economy itself, local administration, and regional spatial planning or any other socio-economic field dealing with geographically referenced data can make use of our game concept. The framework offers enough room for user customizations, e.g., by using their own datasets, different game locations, various game settings (scoring, rules, or time constraints), and topics or teaching goals. The interdisciplinarity can be approached with various teaching goals stimulating particular skills in diverse disciplines, still considering spatial aspects in the respective study field. On top of it, as mentioned in Section 2, our game concept (including games settings, rules, data etc.) is openly published and described in full detail on the project website. As part of moving forward with the Spationomy project, the decision was made to begin including researchers and students with a background in game studies within the Humanities. This step ensures a more critical perspective on how game design decisions relating to the content the game wants to address in terms of persuasive strategies for learning and to improve game flow and meaningful play for learners. As the specific game studies researchers (now participating in the Spationomy follow-up project) have their roots in new media and digital culture studies, the geographical/economic datasets themselves, as well as the tools to gather, process, visualize and play with them, will also be investigated from this new perspective. Both data and data-related tools, as well as the simulations and games we use to play around with them, give shape to the way we understand our world, our society, and our culture [76,77]. This perspective will add another interdisciplinary angle and associated educational potential, which we look forward to exploring further. Returning to what we learned from the project under discussion in this article, a final issue worthy of discussion relates to the data generated by the game itself. With this, we mean data related to gameplay activity, which was not just important for the players while playing, but also for debriefing purposes, which is fundamental for the learning process [73]. Additionally, this data is an input for the aforementioned iterative design process. Unexpectedly and unknown to the design team, in the first year of the simulation game, the computers in the lab were programmed to delete all of the user content at the end of each day. Since we played a simulation game in two days, this caused troubles for some students' teams, as they did not back up their projects. Therefore, we established a platform to share results in the following years. In connection to this issue, we tested what the optimal way to collect students' results after each round is-we experimented with simple email submissions, shared Dropbox/Google Drive folders as well as our e-learning platform. If possible, one software environment, where students can "play" the game as well as hand out the results after each round, would be beneficial. Such a GIS environment is currently not available to our knowledge, and we plan to investigate and even develop this idea further in the up-coming Spationomy 2.0 simulation game.

\section{Conclusions}

Simulation game-based learning is a much more playful and experiential approach to learning when compared to traditional teaching. The overall idea of interdisciplinary and playful learning, representing more attractive and relevant pedagogy, was already investigated in our previous research $[19,72]$. In that research, the integration and use of the interdisciplinary knowledge in the Spationomy project were statistically confirmed, with one of the major findings that students' involvement (in terms of participating on Spationomy activities) has a significant and positive effect on the perceived usefulness of integration and use of interdisciplinary knowledge. This corresponds with students' 
interdisciplinary knowledge acquisition and intention to use it in the future [19,72]. As shown in the current paper, our approach does yield such benefits for interdisciplinary and intercultural learning. This fact leads to the main finding that the complex and data-driven playful activities are viable for interdisciplinary collaboration. Due to gaming settings and the competitive environment (serving rather as a motivation factor than stressful experience), students are more involved and engaged in a learning process. On top of that, when dealing with two distinct topics (geoinformatics and economy), this type of playful education builds a bridge between disciplines, and learners and teachers as well. It all fits well with what Gee describes as those key elements in active and critical learning in/through games. These are (1) learning to experience, see and act on the world in new ways (in this case by making the relationship between spatial and economic data and in the world visible); (2) offering the potential to join and collaborate with a new affinity group (in this case crossing disciplinary boundaries); and (3) developing resources for future learning in relation to other domains to which the game is related [14], p. 45. We nonetheless also identify specific challenges (e.g., time demanding preparations, results sharing platform), that might help others to avoid such obstacles in the creation of their own game. A fourth element for learning via games Gee postulates is that the design spaces of games like the Spationomy simulation game always "engage and manipulate people in certain ways" which also helps shape our view of the world [14], p. 46. A critical look at game design itself, as part of the learning outcome, might thus also provide insight into how a specific use of GIS, and economic data sets and tools matter in the way the world is represented in such games.

Our main aim and next step will be to put the current prototype of the game into a higher level of readiness by more fully engaging with game studies researchers towards the creation of full-fledged Spationomy game experience, and to take the challenges mentioned above into account while doing so. The goal here is not to create a singular game but rather a "plug \& play" compact package, with all supporting guiding materials and methodology that will make it instantly and easily adopted, used, and played elsewhere. This means that play sessions and desired learning outcomes can be tailored to the needs of specific local audiences to make play meaningful and situated, while still offering the interdisciplinary and intercultural set-up at its core. The new stage of the game will keep the spatialeconomic aspect of the simulation but, as indicated earlier, is enhanced by recent advances in game studies and research. The idea is still to bring more spatial and economic science into the gaming domain by tackling the issue of lacking science and real-world situations in educational games. From a game research perspective, however, playing with data sets through game design also has the potential to lay bare the discursive nature of such data and the underlying methods of collection and interpretation [78]. This aligns with Gee's understanding of disciplinary knowledge as "design space" with their own "design grammar" and thereby the need for critical reflection on the rules and technologies used in and thus upholding these knowledge domains [14]. This approach will only further strengthen the interdisciplinary core of the Spationomy project which, to quote earlier map-based learning research [79], Spationomy 2.0, then, is the next step in an ongoing exploration of the potential of play for learning across such divides.

Author Contributions: Conceptualization, Methodology, Writing-Original Draft Preparation, and Visualization: Vít Pászto, Jiři Pánek, René Glas, Jasper van Vught, Funding Acquisition: Vít Pászto. All authors have read and agreed to the published version of the manuscript.

Funding: This research was funded by the European Union, Erasmus+ programme, grant number 2016-1-CZ01-KA203-024040 and 2019-1-CZ01-KA203-061374.

Institutional Review Board Statement: Ethical review and approval were waived for this study, due to not-applicability of the students' survey to the ethical reviewer board at the time.

Informed Consent Statement: Informed consent was obtained from all subjects involved in the study.

Data Availability Statement: Data available on request due to restrictions e.g., privacy or ethical. 
Acknowledgments: The authors would like to acknowledge all the Spationomy team members as well as all participating students, especially those providing the simulation game feedback.

Conflicts of Interest: The authors declare no conflict of interest. The funders had no role in the design of the study; in the collection, analyses, or interpretation of data; in the writing of the manuscript, or in the decision to publish the results.

\section{References}

1. Karakoç, B.; Eryılmaz, K.; Özpolat, E.T.; Yıldırım, I. The Effect of Game-Based Learning on Student Achievement: A Meta-Analysis Study. Technol. Knowl. Learn. 2020, 1-16. [CrossRef]

2. Comenius, J.A. The Great Didactic of John Amos Comeniuso Title; A and C Black: London, UK, 1896.

3. Teplanová, K. Schola Ludus Theory of Teaching and Learning. In Proceedings of the 17th Conference of Slovak Physicists, Prague, Czech Republic, 17-22 May 2009; pp. 7-8.

4. Aberšek, B. Schola Ludus. J. Balt. Sci. Educ. 2016, 15, 556-558.

5. Haverlikova, V. Schola Ludus serious educational games. In Proceedings of the 14th International Conference on Interactive Collaborative Learning, Piestany, Slovakia, 21-23 September 2011; pp. 615-619.

6. Crookall, D. Serious Games, Debriefing, and Simulation/Gaming as a Discipline. Simul. Gaming 2010, 41, 898-920. [CrossRef]

7. Walford, R. Geography games and simulations: Learning through experience. J. Geogr. High. Educ. 1981, 5, 113-119. [CrossRef]

8. McCormick, J. Simulation and Gaming as a Teaching Method. Program. Learn. Educ. Technol. 1972, 9, 198-205. [CrossRef]

9. King, R. To play or not to play: An introduction to games and simulations in geography teaching. J. Geogr. High. Educ. 1981, 5, 111-112. [CrossRef]

10. Jones, D.; Chang, M. Pecunia-a Life Simulation Game for Finance Education. Res. Pract. Technol. Enhanc. Learn. 2014, 9, 7-39.

11. O'Neill, B. Financial simulations for young adults: Making the 'real world' real. J. Ext. 2008, 46, 9-12.

12. Chen, C.H.; Wang, K.C.; Lin, Y.H. The Comparison of Solitary and Collaborative Modes of Game-based Learning on Students' Science Learning and Motivation. J. Educ. Technol. Soc. 2015, 18, 237-248.

13. Tokac, U.; Novak, E.; Thompson, C.G. Effects of game-based learning on students' mathematics achievement: A meta-analysis. J. Comput. Assist. Learn. 2019, 35, 407-420. [CrossRef]

14. Gee, J.P. What Video Games Have to Teach Us About Learning and Literacy; Palgrave Macmillan UK: New York, NY, USA, 2003.

15. Star, S.L. This is Not a Boundary Object: Reflections on the Origin of a Concept. Sci. Technol. Hum. Values 2010, 35, 601-617. [CrossRef]

16. Salen, E.; Tekinbaş, K.; Zimmerman, K.S. Rules of Play: Game Design Fundamentals; MIT Press: Cambridge, MA, USA, 2004.

17. Paszto, V.; Burian, J.; Panek, J.; Macku, K. Mapping the economic data-Case studies and best practices. In International Multidisciplinary Scientific GeoConference Surveying Geology and Mining Ecology Management; SGEM: Albena, Bulgaria, 2017; Volume 17. [CrossRef]

18. Jürgens, C.; Moos, N.; Redecker, A.P. Spationomy—Spatial exploration of economic data—An interdisciplinary geomatics project. Kartogr. Nachr. 2018, 2018, 66-71. [CrossRef]

19. Zabukovšek, S.S.; Tominc, P.; Bobek, S.; Štrukelj, T. Spatial Exploration of Economic Data-Insight Into Attitudes of Students Towards Interdisciplinary Knowledge. ISPRS Int. J. Geo-Inf. 2020, 9, 421. [CrossRef]

20. Twelker, P.A. Some reflections on instructional simulation and gaming. Simul. Games 1972, 3, 147-153. [CrossRef]

21. Csikszentmihalyi, M. Flow: The Psychology of Happiness; Harper Perennial: New York, NY, USA, $1990 ;$ p. 334.

22. Krek, A. Games in Urban Planning: The Power of a Playful Public Participation. Proceedings of the REAL CORP 2008: Mobility Nodes as Innovation Hubs 2, 683-691.

23. Gould, P.R. Man against His Environment: A Game Theoretic Framework. Ann. Assoc. Am. Geogr. 1963, 53, 290-297. [CrossRef]

24. Conolly, G. The use of four selected games in a tertiary geography programme. J. Geogr. High. Educ. 1981, 5, 121-132. [CrossRef]

25. Healey, M.; Jenkins, A. Kolb's Experiential Learning Theory and Its Application in Geography in Higher Education. J. Geogr. 2000, 99, 185-195. [CrossRef]

26. Lambert, J. Digital Storytelling: Capturing Lives, Creating Community, 2nd ed.; Digital Diner Press: Berkeley, CA, USA, 2006.

27. Kerski, J.J. Geo-awareness, Geo-enablement, Geotechnologies, Citizen Science, and Storytelling: Geography on the World Stage. Geogr. Compass 2015, 9, 14-26. [CrossRef]

28. Poplin, A. Playful public participation in urban planning: A case study for online serious games. Comput. Environ. Urban Syst. 2012, 36, 195-206. [CrossRef]

29. Kim, M.; Shin, J. The Pedagogical Benefits ofSimCityin Urban Geography Education. J. Geogr. 2016, 115, 39-50. [CrossRef]

30. Minović, D.; Milovanović, M.; Starcevic, M. Literature review in game-based learning. In World Summit on Knowledge Society; Springer: Berlin/Heidelberg, Germany, 2011; pp. 146-154.

31. Raghothama, J.; Meijer, S.A. A Review of Gaming Simulation in Transportation. Min. Data Financ. Appl. 2014, 8264, 237-244. [CrossRef]

32. Ge, X.; Ifenthaler, D. Information Resources Management Association Designing Engaging Educational Games and Assessing Engagement in Game-Based Learning. In Gamification in Education; IGI Global: Hershey, PA, USA, 2018; pp. 1-19.

33. Dillon, B.A. Signifying the west: Colonialist design in Age of Empires III: The WarChiefs. Eludamos. J. Comput. Game Cult. 2008, $2,129-144$ 
34. Pearce, C. Towards a game theory of game. First Pers. New Media Story Perform. Game 2004, 1, 143-153.

35. List, L.; Bryant, B. Using Minecraft to encourage critical engagement of geography concepts. In Proceedings of the Society for Information Technology \& Teacher Education International Conference, Heraklion, Greece, 17 March 2014; pp. $2384-2388$.

36. Nebel, S.; Schneider, S.; Rey, G.D. Mining learning and crafting scientific experiments: A literature review on the use of Minecraft in education and research. Educ. Technol. Soc. 2016, 19, 355-366.

37. Scarlett, M. Gaming geography: Using Minecraft to teach essential geographic skills. In Proceedings of the Society for Information Technology \& Teacher Education International Conference, Washington, DC, USA, 26-30 March 2015; pp. 838-840.

38. Bos, B.; Wilder, L.; Cook, M.; O’Donnell, R. Learning Mathematics through Minecraft. Teach. Child. Math. 2014, 21, 56-59. [CrossRef]

39. Cipollone, M.; Schifter, C.C.; Moffat, R.A. Minecraft as a creative tool: A case study. Int. J. Game-Based Learn. 2014, 4, 1-14. [CrossRef]

40. Short, D. Teaching scientific concepts using a virtual world-Minecraft. Teach. Sci. J. Aust. Sci. Teach. Assoc. 2012, 58, 55.

41. Cheng, Z.; Hao, F.; Jianyou, Z.; Yun, S. Research on design of serious game based on GIS. In Proceedings of the 2010 IEEE 11 th International Conference on Computer-Aided Industrial Design \& Conceptual Design 1, Yiwu, China, 17-19 November 2010; Volume 1, pp. 231-233.

42. Huang, C.; Zhang, X. E-Game Learning Model for GIS Education. In Proceedings of the 2010 International Conference on Multimedia Technology, Hong Kong, China, 28-30 December 2010; pp. 1-4.

43. Poplin, A. Games and Serious Games in Urban Planning: Study Cases. Comput. Vis. 2011, 6783, 1-14. [CrossRef]

44. Foth, M.; Bajracharya, B.; Brown, R.; Hearn, G. The Second Life of urban planning? Using NeoGeography tools for community engagement. J. Locat. Based Serv. 2009, 3, 97-117. [CrossRef]

45. Reinart, B.; Poplin, A. Games in urban planning-A comparative study. In Proceedings of the REAL CORP 2014, Vienna, Austria, 21-23 May 2014; pp. 49-56.

46. Ampatzidou, C.; Gugerell, K. Mapping Game Mechanics for Learning in a Serious Game for the Energy Transition. Int. J. E-Plan. Res. 2019, 8, 1-23. [CrossRef]

47. Stojšić, I.; Džigurski, A.I.; Maričić, O.; Bibić, L.I.; Vučković, S.Đ. Possible Application of Virtual Reality in Geography Teaching. J. Subj. Didact. 2016, 1, 83-96. [CrossRef]

48. Trindade, M.J.D.S.; Santos, C.A.D. Virtual Reality in the Classroom: Geography Teaching Practice. Geosaberes 2019, 22, 72-80. [CrossRef]

49. Šašinka, Č.; Stachoň, Z.; Sedlák, M.; Chmelík, J.; Herman, L.; Kubíček, P.; Šašinková, A.; Doležal, M.; Tejkl, H.; Urbánek, T.; et al. Collaborative Immersive Virtual Environments for Education in Geography. ISPRS Int. J. Geo-Inf. 2019, 8, 3. [CrossRef]

50. Turan, Z.; Meral, E.; Şahin, I.F. The impact of mobile augmented reality in geography education: Achievements, cognitive loads and views of university students. J. Geogr. High. Educ. 2018, 42, 427-441. [CrossRef]

51. Tomaszewski, B.M.; Walker, A.; Gawlik, E.; Lane, C.; Williams, S.; Orieta, D.; McDaniel, C.; Plummer, M.; Nair, A.; Jose, N.S.; et al. Supporting Disaster Resilience Spatial Thinking with Serious GeoGames: Project Lily Pad. ISPRS Int. J. Geo-Inf. 2020, 9 , 405. [CrossRef]

52. Olszewski, R.; Cegiełka, M.; Szczepankowska, U.; Wesołowski, J. Developing a Serious Game That Supports the Resolution of Social and Ecological Problems in the Toolset Environment of Cities: Skylines. ISPRS Int. J. Geo-Inf. 2020, 9, 118. [CrossRef]

53. De Andrade, B.; Poplin, A.; de Sena, Í.S. Minecraft as a Tool for Engaging Children in Urban Planning: A Case Study in Tirol Town, Brazil. ISPRS Int. J. Geo-Inf. 2020, 9, 170. [CrossRef]

54. Faria, A.; Hutchinson, D.; Wellington, W.J.; Gold, S. Developments in Business Gaming. Simul. Gaming 2009, 40, 464-487. [CrossRef]

55. Gagnon, J.H. The Mother of Soviet Simulation Gaming. Simul. Games 1987, 18, 3-12. [CrossRef]

56. Abt, C.C. Serious Games; The Viking Press: New York, NY, USA, 1970.

57. Nesbitt, W.A. Simulation Games for the Social Studies Classroom; Foreign Policy Association: New York, NY, USA, 1971.

58. Strum, I. Games for School Use; Centre for Educational Research: New York, NY, USA, 1969.

59. Meadows, D.H.; Meadows, D.L.; Randers, J.; Behrens, W.W. The Limits to Growth; Universe Books; Potomac Associates: New York, NY, USA, 1972.

60. Dede, C. Theoretical perspectives influencing the use of information technology in teaching and learning. In International Handbook of Information Technology in Primary and Secondary Education, 20th ed.; Voogt, J., Knezek, G., Eds.; Springer: New York, NY, USA, 2008; pp. 43-62.

61. Crawford, C. The Art Game Computer Game Design. 1982. Available online: http://www.stonetronix.com/gamedesign/art_of_ computer_game_design.pdf (accessed on 11 November 2020).

62. Pászto, V.; Pánek, J. Spationomy Simulation Game. In Spationomy: Spatial Exploration of Economic Data and Methods of Interdisciplinary Analytics; Pászto, V., Jürgens, C., Tominc, P., Burian, J., Eds.; Springer: Berlin/Heidelberg, Germany, 2020 ; pp. 305-325.

63. Juul, J. The Game, the Player, the World: Looking for a Heart of Gameness. PLURAIS-Rev. Multidiscip. 2010, 1, 30-45. [CrossRef]

64. Brakman, S.; Garretsen, H.; Van Marrewijk, C. The New Introduction to Geographical Economics; Cambridge University Press (CUP): Cambridge, UK, 2009.

65. Redding, S.J.; Rossi-Hansberg, E. Quantitative Spatial Economics. Annu. Rev. Econ. 2016, 9, 21-58. [CrossRef] 
66. Lesage, J. Spatial econometrics. In Handbook of Research Methods and Applications in Economic Geography; Edward Elgar Publishing: Cheltenham, UK, 2015; pp. 23-40.

67. Nitsche, M. Video Game Spaces: Image, Play, and Structure in 3D Worlds; MIT Press: Cambridge, MA, USA, 2008.

68. Huff, D.L. A Note on the Limitations of Intraurban Gravity Models. Land Econ. 1962, 38, 64. [CrossRef]

69. Huff, D.L. A Probabilistic Analysis of Shopping Center Trade Areas. Land Econ. 1963, 39, 81. [CrossRef]

70. Davis, F.D. Perceived Usefulness, Perceived Ease of Use, and User Acceptance of Information Technology. MIS Q. 1989, 13, 319-340. [CrossRef]

71. Venkatesh, V.; Davis, F.D. A Theoretical Extension of the Technology Acceptance Model: Four Longitudinal Field Studies. Manag. Sci. 2000, 46, 186-204. [CrossRef]

72. Tominc, P.; Paszto, V.; Bobek, S.; Zabukovšek, S.S. Integration and Use of the Interdisciplinary Knowledge in the Field of Spatial and Economics/Business Sciences. Croat. J. Educ. 2019, 21, 861-892. [CrossRef]

73. Crookall, D. Engaging (in) Gameplay and (in) Debriefing. Simul. Gaming 2014, 45, 416-427. [CrossRef]

74. Stebbins, R. Exploratory Research in the Social Sciences. In Exploratory Research in the Social Sciences; SAGE Publications Ltd.: Thousand Oaks, CA, USA, 2001; pp. 2-18.

75. Heath, R. Geography games and simulations. In Proceedings of the Geographical Association Conference, London, UK, 29 August-1 September 2017.

76. van Es, K.; Schäfer, M.T. The Datafied Society. Studying Culture through Data; Amsterdam University Press: Amsterdam, The Netherlands, 2017.

77. Glas, R.; Lammes, S.; de Lange, M.; Raessens, J.; de Vries, I. The Playful Citizen: Civic Engagement in a Mediatized Culture; Amsterdam University Press: Amsterdam, The Netherlands, 2019.

78. Glas, R.; van Vught, J.; Werning, S. Thinking Through' Games in the Classroom: Using Discursive Game Design to Play and Engage with Historical Datasets. Trans. Digit. Games Res. Assoc. J. Available online: https:/ /www.semanticscholar.org/paper/\%E2\%80\% 98Thinking-through\%E2\%80\%99-games-in-the-classroom\%3A-Using-toGlas/a83e4a1b4dd72b9d34230f32748763bfd72507f0 (accessed on 10 February 2021).

79. Pánek, J.; Gekker, A.; Hind, S.; Wendler, J.; Perkins, C.; Lammes, S. Encountering Place: Mapping and Location-Based Games in Interdisciplinary Education. Cartogr. J. 2018, 55, 285-297. [CrossRef] 